\title{
Hemorrhoidectomy versus rubber band ligation in grade III hemorrhoidal disease: a large retrospective cohort study with long-term follow-up
}

\author{
Lisette Dekker, ${ }^{1,2}$, Michiel T.J. Bak ${ }^{1,3}$, Willem A. Bemelman ${ }^{2}$, Richelle J.F. Felt-Bersma ${ }^{1,4}$, Ingrid J.M. Han-Geurts ${ }^{1}$ \\ ${ }^{1}$ Department of Surgery, Proctos Kliniek, Bilthoven; ${ }^{2}$ Department of Surgery, Amsterdam University Medical Centre, Amsterdam; ${ }^{3}$ Department of \\ Surgery, University Medical Centre Utrecht, Utrecht; ${ }^{4}$ Department of Gastroenterology and Hepatology, Amsterdam University Medical Centre, \\ Amsterdam, The Netherlands
}

Purpose: Standard therapy for grade III hemorrhoids is rubber band ligation (RBL) and hemorrhoidectomy. The longterm clinical and patient-reported outcomes of these treatments in a tertiary referral center for proctology were evaluated. Methods: A retrospective analysis was performed in all patients with grade III hemorrhoids who were treated between January 2013 and August 2018. Medical history, symptoms, reinterventions, complications, and patient-reported outcome measurements (PROM) were retrieved from individual electronic patient files, which were prospectively entered as standard questionnaires in our clinic.

Results: Overall, 327 patients (163 males) were treated by either RBL $(n=182)$ or hemorrhoidectomy $(n=145)$. The median follow-up was 44 months. The severity of symptoms and patient preference led to the treatment of choice. The most commonly experienced symptoms were prolapse (83.2\%) and blood loss (69.7\%). Hemorrhoidectomy was effective in $95.9 \%$ of the cases as a single procedure, while a single RBL procedure was only effective in $51.6 \%$. In the RBL group, $34.6 \%$ received a second RBL session. Complications were not significantly different, 11 (7.6\%) after hemorrhoidectomy versus 6 (3.3\%) after RBL. However, 4 fistulas developed after hemorrhoidectomy and none after RBL $(\mathrm{P}<0.05)$. The preprocedure PROM score was higher in the hemorrhoidectomy group whereas the post-procedure PROM score did not significantly differ between the groups.

Conclusion: Treatment of grade III hemorrhoids usually requires more than one session RBL whereas 1-time hemorrhoidectomy suffices. Complications were more common after hemorrhoidectomy. The patient-related outcome did not differ between procedures.

Keywords: Hemorrhoids; Rubber band ligation; Hemorrhoidectomy; Reintervention; Patient outcome assessment

\section{INTRODUCTION}

Hemorrhoids are 1 of the most common anorectal disorders [1] with an estimated prevalence up to $39 \%$ in the general population

Received: Nov 24, 2020 - Revised: Jan 15, 2021 - Accepted: Feb 1, 2021 Correspondence to: Lisette Dekker, M.D.

Department of Surgery, Amsterdam University Medical Centre, location AMC, Meibergdreef 9, 1105 AZ Amsterdam, The Netherlands

Tel: +31-612204316, Fax: +31-302282934

E-mail: I.dekker22@amsterdamumc.nl

ORCID: https://orcid.org/0000-0001-8092-7196

(C) 2022 The Korean Society of Coloproctology

This is an open-access article distributed under the terms of the Creative Commons Attribution NonCommercial License (https://creativecommons.org/licenses/by-nc/4.0) which permits unrestricted noncommercial use, distribution, and reproduction in any medium, provided the original work is properly cited. by screening colonoscopies. Of these, $45 \%$ experienced complaints [2]. Patients suffering from hemorrhoidal disease complain of blood loss, soiling, anal pain, prolapse, and pruritus.

Initial management of hemorrhoids is conservative and consists of lifestyle-, diet-, and toilet behavior advice [3]. In case of persisting symptoms in grade II and III hemorrhoids, the next step is usually a nonsurgical office-based procedure like rubber band ligation (RBL), injection sclerotherapy, or infrared coagulation. The most popular nonsurgical procedure is $\mathrm{RBL}[4,5]$ which is considered first-line therapy for grade I to III in several guidelines [6-8]. Although complications are rare, recurrence is common and repeated rubber banding may be required [9]. Surgery is reserved for grade IV hemorrhoids or those which failed nonsurgical treatment $[10,11]$. Besides traditional excisional hemorrhoid- 
ectomy, multiple other procedures have been developed with the intention to decrease postoperative discomfort such as hemorrhoidal artery ligation, stapled hemorrhoidectomy with mucopexy, hemorrhoidoplasty, and radiofrequency ablation [9, 12-14]. Despite the variety of surgical procedures, traditional excisional hemorrhoidectomy has proven to be the most clinical and costeffective procedure and is therefore still considered the gold standard $[9,13,15]$.

A recent national survey among Dutch colorectal surgeons demonstrated varying practices in the treatment of hemorrhoids [16]. A similar survey was conducted in Italy including more than 32,000 patients [17]. Literature data on the clinical outcome of treatment for specifically grade III hemorrhoids are rare. The only published systematic review, in which 3 small heterogeneous trials were analyzed, was in favor of hemorrhoidectomy because of a lower frequency of retreatment [18]. Dutch, and recently developed European Society of Coloproctology (ESCP) guidelines provides guidance on the most effective (surgical) treatment for patients with hemorrhoidal disease $[19,20]$. In summary, RBL is the preferred treatment in grade I and II with a maximum of 4 sessions and in grade IV surgical intervention is recommended. In case of grade III, both guidelines are inconclusive; RBL can be considered as the first treatment before surgery is considered [19].

The aim of the present study was to evaluate clinical and patientreported results of treatment of grade III hemorrhoids by RBL and excisional hemorrhoidectomy in a tertiary referral center.

\section{METHODS}

\section{Study design and study population}

The Proctos Kliniek is a tertiary center for proctology with 5 experienced proctologic surgeons. This single-center cohort study was conducted between January 1, 2013 and August 1, 2018. All patients aged 18 years and above who were diagnosed with grade III hemorrhoids and treated by RBL or hemorrhoidectomy were included. All patients gave written informed consent for the procedure. Exclusion criteria were injection sclerotherapy or RBL in the past 3 years, prior proctologic surgical interventions, anal or rectal radiotherapy, anorectal malignancy, known inflammatory bowel disease, or spinal cord injury.

Diagnosis and grading were established by the treating surgeons by medical history, physical examination, and proctoscopy. When indicated, a colonoscopy was performed to exclude pathology other than hemorrhoids. Depending on the severity of symptoms, RBL and hemorrhoidectomy were both explained and offered to all patients presenting for the first time with symptomatic hemorrhoids grade III unless contraindicated, following Dutch and ESCP guidelines. After initial clinical assessment and counseling, a definite choice of treatment was made following the concept of shared decision-making.

Demographic and clinical variables were prospectively recorded and could be retrieved from medical records. Follow-up data were recorded for a minimum of 1 year after the last intervention. As part of our policy and patient care, upon visiting our clinic all patients are asked for the consent of using their medical data anonymous for future research and permission to approach them for subsequent follow-up. In case permission is not granted, a notification in the electronic patient file is made.

\section{Primary and secondary endpoints}

The primary outcome was clinical effectiveness measured as reintervention within 1 year after the procedure.

Secondary outcomes were: (1) number of reinterventions within 1 year, (2) postoperative complications (hemorrhage requiring hospitalization, emergency reoperation, or blood transfusion; acute hemorrhoidal thrombosis; perianal fistula; urinary retention requiring catheterization, fissure in ani; and fecal incontinence), and (3) the patient-reported outcome measurements (PROM) score.

Complications as hemorrhages and anal fistulas were classified by Clavien-Dindo (CD) classification [21]. Only grade 2 and above were documented.

The proctology specific PROM score (Proctoprom) is a questionnaire comprising of 5 questions concerning the impact of proctologic symptoms on well-being (suffering from anal symptoms during daily activities, toilet visit, social activities, relationship and intimacy, and worrying about complaints) and is used for many years in our clinic to evaluate the treatment. The PROM questionnaire has a score range from 0 to 10 per question and the actual score is the mean of the 5 questions, 0 being perfect and 10 could not be worse. All items but 1 are mandatory. If 4 items are scored, the PROM score is calculated as the average of the 4 questions. In February 2020, the validated Proctoprom was published [22]. The questionnaires were recorded during the first outpatient visit (PROM1) and after the intervention (PROM2). Unfortunately, PROM2 was not collected after their last visit to the clinic in all patients. Therefore, all patients were approached by e-mail and received another questionnaire in 2019, thus extending the follow-up by PROM2.

\section{Interventions}

RBL was performed in an outpatient setting. Via the proctoscope (18 mm, Sapi Med S.p.A., Alessandria, Italy), a device (Haemoband disposable ligator, Leichhardt, NSW, Australia) was placed and the rubber band was applied at the base of hemorrhoid. A maximum of 3 to 4 bands was used per session. Oral analgesics were recommended before the intervention to reduce pain afterward.

Traditional excisional hemorrhoidectomy was performed by using the closed technique (Ferguson and Heaton [11]) with diathermy with the patient positioned in a lithotomy position. The procedure was performed under anesthesia in a day-care setting. All patients received postoperative laxatives and oral analgesics. Opioids were administered when necessary, and no antibiotics 
were prescribed. All interventions were performed by 1 of the 5 experienced proctologic surgeons.

\section{Statistical analysis}

Descriptive statistical analyses (frequency, percentage, mean, and interquartile range) were performed to describe the research sample and questionnaire items. Categorical outcome data were analyzed using the chi-square test. To evaluate treatment, the 2 PROM questionnaires (before and after the procedure) were compared in each group using the paired t-test. Comparison be-

Table 1. Baseline characteristics with patient reported symptoms

\begin{tabular}{lccc}
\hline Characteristic & $\begin{array}{c}\text { Rubber band ligation } \\
(\mathrm{n}=182)\end{array}$ & $\begin{array}{c}\text { Hemorrhoidectomy } \\
(\mathrm{n}=145)\end{array}$ & P-value \\
\hline Sex & & & 0.657 \\
$\quad$ Male & $93(51.1)$ & $70(48.3)$ & \\
$\quad$ Female & $90(49.5)$ & $76(52.4)$ & \\
Age (yr) & $55(26-92)$ & $52(24-78)$ & 0.078 \\
Symptom & & & \\
Blood loss & $125(68.7)$ & $103(71.0)$ & 0.717 \\
Soiling & $56(30.8)$ & $52(35.9)$ & 0.346 \\
Anal pain & $59(32.4)$ & $59(40.7)$ & 0.133 \\
Prolapse & $151(83.0)$ & $121(83.4)$ & $>0.999$ \\
Pruritis & $23(12.6)$ & $23(15.9)$ & 0.427 \\
No. of piles & & & \\
1 & $88(48.4)$ & $64(44.1)$ & 0.106 \\
2 & $49(27.0)$ & $57(39.3)$ & 0.075 \\
3 & $28(15.4)$ & $24(16.6)$ & 0.793 \\
\hline
\end{tabular}

Values are presented as number (\%) or median (range).

aThe number of piles in 17 patients in the rubber band ligation group was unknown. tween these groups was measured with the unpaired samples $t$ test. A 2-sided P-value of $<0.05$ was considered statistically significant. IBM SPSS Statistics for Windows ver. 25.0 (IBM Corp., Armonk, NY, USA) was used.

\section{RESULTS}

\section{Patient and treatment characteristics}

Overall, 552 patients were referred with hemorrhoidal disease grade 3 and treated by RBL or hemorrhoidectomy. A total of 225 patients were excluded due to exclusion criteria and 327 were included in the study. They were treated by RBL $(\mathrm{n}=182)$ or hemorrhoidectomy $(\mathrm{n}=145)$. The median age was 54 years (range, 24-92 years) and did not differ between the groups. Males and females were equally distributed in both groups.

Although grade III hemorrhoids are defined by prolapse, 16.8\% did not experience this as the main symptom (Table 1). There were no significant differences in distribution between treatment groups in the number of piles affected.

In 94 patients (51.6\%), a single RBL was sufficient. Of the $88 \mathrm{pa}-$ tients who needed further treatment, 63 patients $(71.6 \%)$ underwent a second RBL session within 1 year and 25 (28.4\%) underwent a hemorrhoidectomy (Fig. 1). Of the patients who underwent a hemorrhoidectomy, 139 (95.9\%) were treated by this single procedure (Fig. 2).

\section{Complications}

Complications following hemorrhoidectomy and RBL occurred in 11 patients (7.6\%) versus 6 patients $(3.3 \%)$ respectively; this difference was not significant (Table 2). Four fistulas developed after hemorrhoidectomy and none in the RBL group $(\mathrm{P}<0.05)$. All 4 complications are classified as CD III (major). Two were intersphincteric fistulas and both were noticed 4 weeks after hemor-

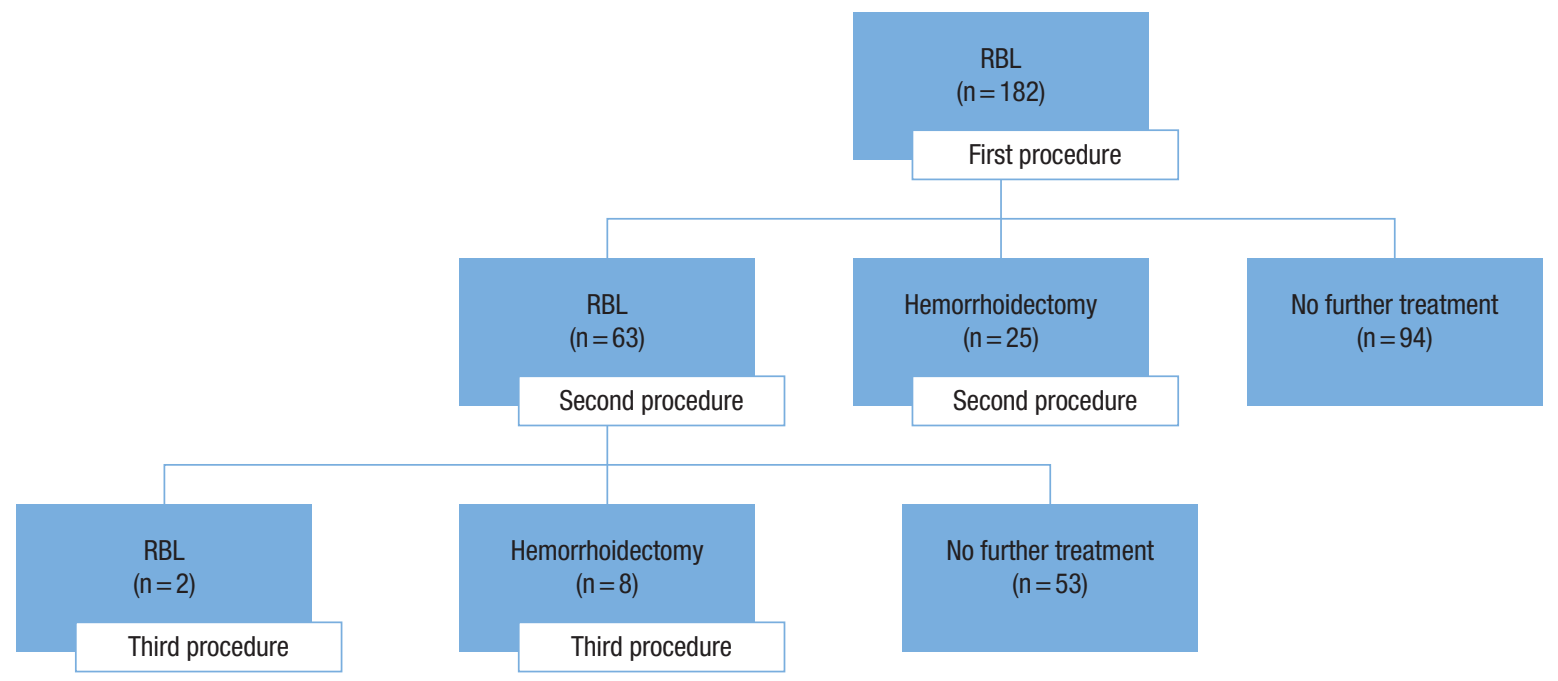

Fig. 1. Flowchart of further treatment after rubber band ligation (RBL) within 1 year. 


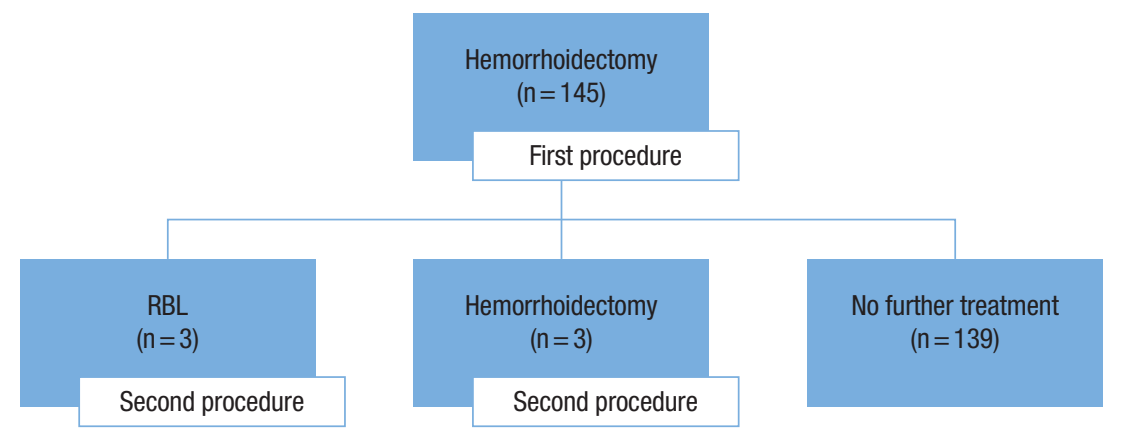

Fig. 2. Flowchart further treatment after hemorrhoidectomy within 1 year. RBL, rubber band ligation.

Table 2. Complications after first treatment

\begin{tabular}{lccc}
\hline Complication & $\begin{array}{c}\text { Rubber band } \\
\text { ligation } \\
(\mathrm{n}=182)\end{array}$ & $\begin{array}{c}\text { Hemorrhoidectomy } \\
(\mathrm{n}=145)\end{array}$ & P-value \\
\hline Hemorrhage & 3 & 0 & 0.120 \\
Urinary retention & 1 & 4 & 0.106 \\
Acute thrombosed hemorrhoid & 1 & 2 & 0.434 \\
Fistula ani & 0 & 4 & 0.024 \\
Fecal incontinence & 0 & 0 & - \\
Fissure in ani & 1 & 1 & 0.747 \\
Total & 6 & 11 & 0.083 \\
\hline
\end{tabular}

rhoidectomy. One was treated by seton placement followed by fistulotomy and 1 by suturing the internal opening and filling the fistula tract with Permacol paste (Covidien-Metronic, Trévoux, France). Two fistulas were subcutaneous, of which 1 was noticed 8 weeks and another 16 weeks after hemorrhoidectomy. Both were treated by fistulotomy.

Post-banding hemorrhage developed in 3 patients of which 2 can be classified as CD II (minor) and 1 as CD III (major), all 3 needed hospital admission. In 1 patient the hemorrhage occurred under anticoagulation requiring blood transfusion and in $1 \mathrm{pa}-$ tient blood transfusion was indicated but the patient refused for religious reasons. In another patient, the hemorrhage occurred after 4 weeks and required an emergency reoperation. One of the 33 patients, who underwent a hemorrhoidectomy after primary RBL treatment, an abscess developed that required drainage.

\section{Patient-reported outcome measurements score}

The baseline PROM1 score before the procedure was available in 229 patients (70.0\%); 125 in the RBL group and 104 in the hemorrhoidectomy group (Fig. 3). The PROM2 (post-procedure) was available in 195 patients (59.6\%); 106 in the RBL group and 89 in the hemorrhoidectomy group. In 142 patients both scores were available. There were no differences in PROM score between the groups who returned one of the 2 questionnaires and those who returned both. Therefore, both groups were combined.

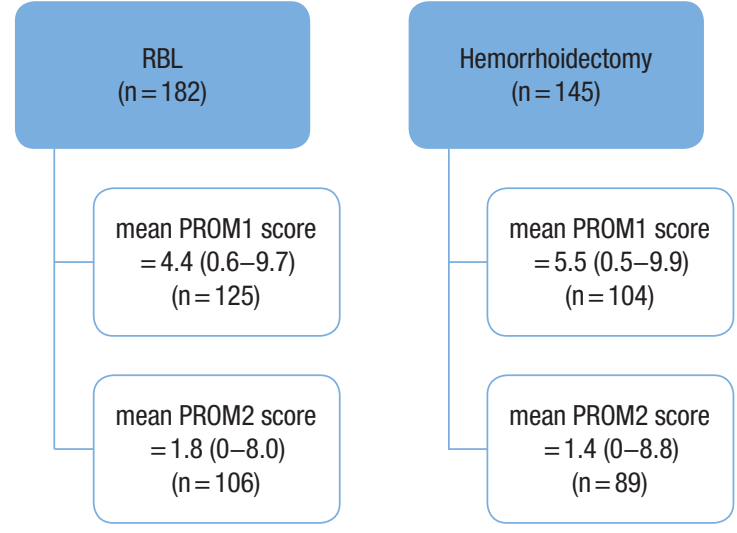

Fig. 3. Flowchart of patient-reported outcome measurements (PROM) scores. PROM score ranges from 0 to 10 with 0 being perfect and 10 could not be worse. PROM1 was administered during the first outpatient visit and PROM2 after treatment.

The mean PROM1 score in RBL was $4.4(0.6-9.7)$ and in the hemorrhoidectomy group 5.5 (0.5-9.9), which was a significant difference $(\mathrm{P}<0.001)$. The median follow-up with the PROM2 was 44 months (range, 10-76 months). The PROM2 was significantly decreased after both RBL $(1.8, \mathrm{P}<0.001)$ and hemorrhoidectomy $(1.4, \mathrm{P}<0.001)$. With the independent samples t-test, no significant difference was found between the final PROM2 (postprocedure) score between the RBL and hemorrhoidectomy group $(\mathrm{P}=0.087)$. The mean PROM2 after 2 sessions RBL was 2.3. When comparing the PROM2 in patients who underwent 2 sessions RBL (mean, 2.3) and patients who underwent 1 hemorrhoidectomy (mean, 1.4), this difference was statistically significant $(\mathrm{P}=0.015)$.

\section{DISCUSSION}

This study describes the clinical results of traditional excisional hemorrhoidectomy and RBL in grade III hemorrhoids in a tertiary center for proctology. This is the first study reporting on outcomes using a proctology-specific PROM concerning patient's well-being and social activities - instead of symptom severity-at a long-term follow-up. RBL is often considered as a treatment of 
choice in grade III hemorrhoids because it is a faster, less expensive way and does not require anesthesia compared to a hemorrhoidectomy. However, in our series, we found that $44.3 \%$ of patients underwent hemorrhoidectomy. After the initial consultation, performing physical examination and proctoscopy, extensive information was given on the disease and treatment options were discussed. Patients' choice of treatment was made by shared decision-making. It is likely that patient preference and perhaps also doctor's preference is largely responsible for the relatively high numbers of surgery in this study. Doctor's preference is a phenomenon not unknown and may be diminished by increasing the level of evidence for best treatment [16].

The clinical effectiveness of hemorrhoidectomy in this study, defined as no need for reintervention, is in concordance with existing literature $[13,18,23]$. The proportion of patients in our study who needed only 1 or 2 RBL sessions in 1 year was $80.8 \%$. In current literature, the success rate of $\mathrm{RBL}$, as a single procedure, varies between $49 \%$ and $88 \%[9,13,18,24,25]$. When considering repeated banding as part of the treatment, as has been suggested by the authors of the HubBLe trial [9], both procedures are equally effective, as shown in the current study. The wide variation in success rates reported in the literature of RBL and hemorrhoidectomy can be explained by heterogeneity in outcome reporting making comparison of results difficult and hard to interpret. Recently, van Tol et al. [26] developed the first ESCP Core Outcome Set for hemorrhoidal disease in an international Delphi study with the perspective to improve the quality and uniformity of future research. The PROM in this study attempts to give insight into severity of patient's complaints. Regrettably in our study follow-up PROM data had a wide range. Taking a convalescence period of 6 to 12 weeks into account evaluation of treatment with a PROM questionnaire by then would be ideal. In the study context, this may be extended to 12 months.

More postoperative complications were observed in the hemorrhoidectomy group compared to the $\mathrm{RBL}$ group $(\mathrm{P}=0.08)$. Although hemorrhage is more often described after hemorrhoidectomy [18], this was not the case in our study. The only 3 , relevant, post-procedure bleeding occurred in patients who underwent RBL. This might be due to heterogeneity as none of the included studies in this systematic review clearly described how this outcome was defined [18]. Oozing blood during hemorrhoidectomy can occur but can be managed adequately during surgery. Postbanding hemorrhage is a well-known complication, often classified as minor and occurs mostly after a few days. The bleeding focus is often not so easily visible and therefore more difficult to control. One patient in our study developed a hemorrhage after 4 weeks which is quite late. In rare cases, post-banding hemorrhage may be life-threatening [27].

In literature, post-RBL or postoperative pain has frequently been measured using a visual analog scale or documented as mild, moderate, or severe pain $[9,25]$. In our study, patients are telephone interviewed by a physician assistant to evaluate their well- being a few days after the procedure. This was, unfortunately, not documented by a categorical scale.

Other complications can be pelvic infections. Although serious infections following RBL are rare, pelvic sepsis can be lethal if not early recognized [28-32]. In our cohort, there were no such complications. Unfortunately, 4 of 145 postoperative fistulas were reported after hemorrhoidectomy $(\mathrm{P}=0.024)$ in our study. This compared to 2 of 358 in the eTHoS trial [13].

Patients undergoing hemorrhoidectomy had a significantly higher initial PROM than those who underwent RBL (5.5 versus 4.2). This suggests that patients treated by hemorrhoidectomy suffered from more severe or disabling complaints and were therefore treated by a more invasive procedure than those with milder complaints. The number of affected piles did not seem important in this aspect as 3 piles hemorrhoids were equally distributed among both groups. PROM2 in patients who underwent 2 sessions RBL was significantly higher than in patients who underwent 1 hemorrhoidectomy, which suggests that patients were better off after surgery. There is no comparative literature on this issue.

The most widely used description for the hemorrhoidal disease is Goligher's classification, which ranks the severity of prolapse into 4 grades. The choice of treatment is mostly based on this gradation. However, the experienced symptoms do not always reliably relate to Goligher's classification [33]. Furthermore, the classification does not take into account symptoms as pain, itching, bleeding, or soiling, neither the number of piles prolapsing. A single prolapsed pile, for instance, can be classified the same as a full circumferential prolapse. This makes evaluation of treatments for a specific grade of hemorrhoidal disease less reliable. We believe patient-reported symptoms are a more reliable display of the actual situation and patient burden (Table 1) and explain the patient-reported prolapse rate of $83.2 \%$.

This study was limited due to its retrospective character. Firstly, the primary outcome of clinical effectiveness could only be measured by the need for reintervention. This is, as described above, unfortunately a measurement that is relative since it is unknown if the patient was actually content when treated by 1 or more procedures or had subsequent treatment elsewhere. Secondly, the follow-up of the PROM2 varied widely (median, 44 months; interquartile range, $10-76$ months). A total of $40.4 \%$ of the patients did not complete the PROM2 (post-procedure). Furthermore, it is unknown if patients fill in the PROM2 while under treatment elsewhere.

This paper demonstrates the need for sufficiently large randomized trials comparing treatments focused on the patient-related outcome. Decision-making, in order to maximize outcome, should be supported by evidence and by patient-related outcome measurements. In our opinion, evaluation of treatment with a PROM questionnaire would be of most value between 6 weeks and 3 months. In the study context, this may be extended to 12 months. Further, quality of life and a cost-effectiveness analysis 
could clarify the impact of the chosen intervention on the patient's life and the Dutch national healthcare system. A large multicenter randomized trial comparing hemorrhoidectomy and RBL has recently started in the Netherlands.

\section{CONFLICT OF INTEREST}

No potential conflict of interest relevant to this article was reported.

\section{FUNDING}

None.

\section{REFERENCES}

1. Nivel Zorgregistraties Eerste Lijn. Incidentie en prevalentie van Hemorroïden in de Nederlandse huisartsenpraktijk naar geslacht in 2018 (per 1000 patiëntjaren) [Internet]. Utrecht, The Netherlands: Nivel; 2018 [cited 2021 Jan 15]. Available from: https:// www.nivel.nl/nl/nivel-zorgregistraties-eerste-lijn/jaarciffers-aandoeningen-huisartsenregistraties.

2. Riss S, Weiser FA, Schwameis K, Riss T, Mittlböck M, Steiner G, et al. The prevalence of hemorrhoids in adults. Int J Colorectal Dis 2012;27:215-20.

3. Ganz RA. The evaluation and treatment of hemorrhoids: a guide for the gastroenterologist. Clin Gastroenterol Hepatol 2013;11: 593-603.

4. Cocorullo G, Tutino R, Falco N, Licari L, Orlando G, Fontana T, et al. The non-surgical management for hemorrhoidal disease. A systematic review. G Chir 2017;38:5-14.

5. Madoff RD, Fleshman JW; Clinical Practice Committee, American Gastroenterological Association. American Gastroenterological Association technical review on the diagnosis and treatment of hemorrhoids. Gastroenterology 2004;126:1463-73.

6. Wald A, Bharucha AE, Cosman BC, Whitehead WE. ACG clinical guideline: management of benign anorectal disorders. Am J Gastroenterol 2014;109:1141-57.

7. Stewart DB, Gaertner WB, Glasgow SC, Herzig DO, Feingold D, Steele SR, et al. The American Society of Colon and Rectal Surgeons clinical practice guidelines for anal squamous cell cancers (Revised 2018). Dis Colon Rectum 2018;61:755-74.

8. Clinical Practice Committee, American Gastroenterological Association. American Gastroenterological Association medical position statement: diagnosis and treatment of hemorrhoids. Gastroenterology 2004;126:1461-2.

9. Brown SR, Tiernan JP, Watson AJ, Biggs K, Shephard N, Wailoo AJ, et al. Haemorrhoidal artery ligation versus rubber band ligation for the management of symptomatic second-degree and third-degree haemorrhoids (HubBLe): a multicentre, open-label, randomised controlled trial. Lancet 2016;388:356-64.

10. Milligan ET, Morgan CN, Jones LE, Officer R. Surgical anatomy of the anal canal, ant the operative treatment of haemorrhoids. Lancet 1937;230:1119-24.

11. Ferguson JA, Heaton JR. Closed hemorrhoidectomy. Dis Colon Rectum 1959;2:176-9.

12. Nisar PJ, Acheson AG, Neal KR, Scholefield JH. Stapled hemorrhoidopexy compared with conventional hemorrhoidectomy: systematic review of randomized, controlled trials. Dis Colon Rectum 2004;47:1837-45.

13. Watson AJ, Hudson J, Wood J, Kilonzo M, Brown SR, McDonald A, et al. Comparison of stapled haemorrhoidopexy with traditional excisional surgery for haemorrhoidal disease (eTHoS): a pragmatic, multicentre, randomised controlled trial. Lancet 2016; 388:2375-85.

14. Béliard A, Labbé F, de Faucal D, Fabreguette JM, Pouderoux P, Borie F. A prospective and comparative study between stapled hemorrhoidopexy and hemorrhoidal artery ligation with mucopexy. J Visc Surg 2014;151:257-62.

15. Simillis C, Thoukididou SN, Slesser AA, Rasheed S, Tan E, Tekkis PP. Systematic review and network meta-analysis comparing clinical outcomes and effectiveness of surgical treatments for haemorrhoids. Br J Surg 2015;102:1603-18.

16. van Tol RR, Bruijnen MP, Melenhorst J, van Kuijk SM, Stassen LP, Breukink SO. A national evaluation of the management practices of hemorrhoidal disease in the Netherlands. Int J Colorectal Dis 2018;33:577-88.

17. Altomare DF, Picciariello A, Pecorella G, Milito G, Naldini G, Amato A, et al. Surgical management of haemorrhoids: an Italian survey of over 32000 patients over 17 years. Colorectal Dis 2018; 20:1117-24.

18. Shanmugam V, Thaha MA, Rabindranath KS, Campbell KL, Steele RJ, Loudon MA. Systematic review of randomized trials comparing rubber band ligation with excisional haemorrhoidectomy. Br J Surg 2005;92:1481-7.

19. De Nederlandse Vereniging voor Heelkunde. Behandelalgoritme symptomatische hemorroïden [Internet]. Utrecht, The Netherlands: De Nederlandse Vereniging voor Heelkunde; 2015 [cited 2021 Jan 15]. Available from: https://richtlijnendatabase.nl/richtlijn/proctologie/behandelalgoritme_symptomatische_hemorroiden.html.

20. van Tol RR, Kleijnen J, Watson AJ, Jongen J, Altomare DF, Qvist N, et al. European Society of ColoProctology: guideline for haemorrhoidal disease. Colorectal Dis 2020;22:650-62.

21. Dindo D, Demartines N, Clavien PA. Classification of surgical complications: a new proposal with evaluation in a cohort of 6336 patients and results of a survey. Ann Surg 2004;240:205-13.

22. Vander Mijnsbrugge GJ, Molenaar C, Buyl R, Westert G, van der Wees PJ. How is your proctology patient really doing? Outcome measurement in proctology: development, design and validation study of the Proctoprom. Tech Coloproctol 2020;24:291-300.

23. Cheng FC, Shum DW, Ong GB. The treatment of second degree haemorrhoids by injection, rubber band ligation, maximal anal dilatation, and haemorrhoidectomy: a prospective clinical trial. 
Aust N Z J Surg 1981;51:458-62.

24. Komborozos VA, Skrekas GJ, Pissiotis CA. Rubber band ligation of symptomatic internal hemorrhoids: results of 500 cases. Dig Surg 2000;17:71-6.

25. Forlini A, Manzelli A, Quaresima S, Forlini M. Long-term result after rubber band ligation for haemorrhoids. Int J Colorectal Dis 2009;24:1007-10.

26. van Tol RR, Kimman ML, Melenhorst J, Stassen LP, Dirksen CD, Breukink SO, et al. European Society of Coloproctology Core Outcome Set for haemorrhoidal disease: an international Delphi study among healthcare professionals. Colorectal Dis 2019;21:57080.

27. Odelowo OO, Mekasha G, Johnson MA. Massive life-threatening lower gastrointestinal hemorrhage following hemorrhoidal rubber band ligation. J Natl Med Assoc 2002;94:1089-92.
28. Albuquerque A. Rubber band ligation of hemorrhoids: a guide for complications. World J Gastrointest Surg 2016;8:614-20.

29. Shemesh EI, Kodner IJ, Fry RD, Neufeld DM. Severe complication of rubber band ligation of internal hemorrhoids. Dis Colon Rectum 1987;30:199-200.

30. O'Hara VS. Fatal clostridial infection following hemorrhoidal banding. Dis Colon Rectum 1980;23:570-1.

31. Wechter DG, Luna GK. An unusual complication of rubber band ligation of hemorrhoids. Dis Colon Rectum 1987;30:137-40.

32. Russell TR, Donohue JH. Hemorrhoidal banding. A warning. Dis Colon Rectum 1985;28:291-3.

33. Gerjy R, Lindhoff-Larson A, Nyström PO. Grade of prolapse and symptoms of haemorrhoids are poorly correlated: result of a classification algorithm in 270 patients. Colorectal Dis 2008;10:694700 . 